\title{
RETOMANDO LOS LÍMITES Y LAS LIMITACIONES DEL “ARCHIPIÉLAGO VERTICAL"
}

\author{
REVISITING THE LIMITS AND LIMITATIONS OF THE \\ "VERTICAL ARCHIPELAGO"
}

\author{
Agustín Llagostera ${ }^{1}$
}

\begin{abstract}
El presente trabajo retoma la problemática de los límites y las limitaciones del "Archipiélago Vertical” planteada hace tres décadas por John V. Murra y a la que todavía no se le ha podido dar una respuesta satisfactoria. Con esto no pretendemos resolver el desafío legado por Murra, sino dar una diferente lectura a la información arqueológica existente y con ello formular una hipótesis que pueda orientar el debate y la búsqueda de respuestas bajo un panorama de mayor amplitud.

Nuestro enfoque se centra en el segmento de la vertiente occidental andina correspondiente al norte del actual territorio chileno, planteando que en esta franja el modelo de verticalidad archipielágica, tal como definido por Murra, se consolidó solamente en el Período Intermedio Tardío.

Con anterioridad (período Medio), la necesidad de complementariedad vertical habría sido resuelta a través del macrosistema orquestado por Tiwanaku, entidad que perfeccionó el "sistema de interacción reticular" (Llagostera 2006), de data anterior, por lo que no necesariamente tuvo que recurrir a colonias.

En el Intermedio Tardío se conjugaron acontecimientos sociopolíticos y eventos medioambientales que motivaron una reestructuración sin precedentes en las tierras altoandinas y en los Valles Occidentales. En estos últimos, las poblaciones vallunas que habían alcanzado su apogeo sociocultural se habrían reestructurado bajo mecanismos que podrían asimilarse a los sistemas de "dualidad". En tanto, las poblaciones del altiplano, que estaban siendo flageladas por una intensa sequía, habrían iniciado un clima de agresión y de violencia hacia las poblaciones de las cabeceras de los valles occidentales para apoderarse de la producción hortícola y de sus tierras. Finalmente, los reductos de estas poblaciones precordilleranas (que originalmente hacían parte de la dualidad valluna) habrían caído en poder de las poblaciones altiplánicas, convirtiéndose en colonias ("islas") de estas últimas, consolidando la estructura de "archipiélago vertical", con cabecera en el altiplano. De esta manera se habría dado forma a los archipiélagos étnicos Caranga, Quillaca y Lipes, que serían los más meridionales del mundo andino.
\end{abstract}

Palabras claves: pukaras (sitios defensivos), Andes Centro Sur, período Intermedio Tardío, archipiélagos étnicos, verticalidad, conflictos étnicos, arqueología del norte de Chile.

The present work returns to the problem of the limits and limitations of the 'vertical archipelago', raised three decades ago by John V. Murra, and which still remains without a satisfactory solution. Rather than resolve the challenge left by Murra, I here offer a different approach to the archaeological information, which leads me to formulate a hypothesis that may guide the debate and search for answers within a wider context.

Concentrating on the Western slopes of the Andes in the North of Chile, I propose that the model of the vertical archipelago, as defined by Murra, was consolidated only in the Late Intermediate Period. During the Middle Horizon, the need for vertical complementarity could have been resolved through the macro-system organized by Tiwanaku, a civilization that perfected the older "system of reticulated interaction" (Llagostera 2006), and did not depend on colonies for access to distant resources. But in the Late Intermediate Period, sociopolitical and environmental events combined to bring about a new form of organization in the Andean highlands and in the Western Valleys of the Pacific. In the latter, populations that had reached their sociocultural upper limit would have been restructured under mechanisms assimilable to those of 'duality'. Meanwhile the highland populations, afflicted by an intense drought, would have unleashed violent attacks against those living in the head-waters of the Western Valleys to get hold of their agricultural lands.

Finally, the remnants of these pre-Andean populations (originally part of the valley dual organization) would have fallen into the hands of the altiplanic populations, becoming colonies ('islands') which consolidated a 'vertical archipelago structure' whose nuclei lay on the Altiplano. In this way were formed the southernmost archipelagoes of the Andean world: Caranga, Quillaca and Lipes.

Key words: Pukaras (defensive sites), South Central Andes, Late Intermediate Period, ethnic archipelagoes, verticality, ethnic conflicts, North Chilean archaeology.

1 Instituto de Investigaciones Arqueológicas y Museo, Universidad Católica del Norte, San Pedro de Atacama, Chile. allagost@ucn.cl; allagostera@vtr.net 
Empezando en 1964 con la descripción del reino lupaca en las riberas del lago Titicaca, he tratado en varias publicaciones de analizar y comprender los aspectos ecológicos de la organización económica andina, verificar su presencia en las diversas regiones del mundo andino y definir los límites temporales y geográficos más allá de los cuales dicho modo de producción fue reemplazado o será sustituido por otros... Las características y las variantes regionales, los límites y las limitaciones del modelo de archipiélago vertical están en debate (Murra 1976:142 y 145).

Murra señalaba que el modelo de archipiélago vertical se caracteriza porque cada etnia se esforzaba por controlar un máximo de pisos y nichos ecológicos para aprovechar los recursos que se daban sólo allí, los cuales quedaban a muchos días de camino del núcleo de poder. Aunque el grueso de la densa población permanecía en el altiplano, la autoridad étnica mantenía colonias permanentes asentadas en la periferia para controlar los recursos alejados. Estas "islas" étnicas, separadas físicamente de su núcleo pero manteniendo con éste un contacto social y un tráfico continuo, formaban un archipiélago, un patrón de asentamiento, según Murra, típicamente andino. Los moradores en las "islas" periféricas formaban parte de un mismo universo con los del núcleo, compartiendo una sola organización social y económica.

Mujica, Rivera y Lynch intentaron verificar en el sur de Perú y en el norte de Chile lo planteado por Murra, en un proyecto que no se concretó pero que teóricamente resultaba una interesante propuesta (Mujica et al. 1983). Ellos señalaban que uno de los aspectos prioritarios por resolver era la antigüedad de este patrón de complementariedad económica puna-costa, y su proceso de desarrollo. Planteaban que no se sabía todavía si se trataba de una institución Inka o si tenía raíces más profundas, pero que, en todo caso, se podía postular razonablemente que tuvo etapas de desarrollo a lo largo del tiempo. Asumiendo que los asentamientos altiplánicos del período Tiwanaku identificados en diversos valles de la costa del extremo sur del Perú y del extremo norte de Chile eran colonias del gran centro urbano y ceremonial de Tiwanaku, se propusieron centrar su trabajo en el estudio de las colonias establecidas en los valles de la vertiente occidental. En consecuencia, postulaban que las evidencias más tempranas de colonias altiplánicas parecían ser las del período Tiwanaku, no desechando la posibilidad de que existieron colonias pre-Tiwanaku.

Muñoz y colaboradores (Muñoz et al. 1987) plantean que los antecedentes arqueológicos avalarían en una primera instancia la hipótesis plateada por Murra, en torno a la multietnicidad vista para los valles de Arica durante el siglo XVII y que al parecer sólo sería la continuidad de un sistema sociopolítico-económico de raíces prehispánicas. Estos autores proponen, como hipótesis, un poblamiento "multiétnico" en el curso medio y alto del valle de Codpa, bajo la forma de una coexistencia económico-social, la cual podría estar políticamente controlada por las etnias costeras durante la época pre-Inka, y que quedaría luego supeditada a la estructura del Estado inkaico, vía poblaciones altiplánicas inkanizadas. Concluyen diciendo que es posible que el real establecimiento de colonias altiplánicas en el área sólo haya coincidido con la llegada del inkario a la zona, que al dominar a las etnias circuntiticaca estaban aprovechando el impulso y los deseos de éstas por establecer colonias en los valles, para instaurar paralelamente y mediante éstas, su administración.

Posteriormente, Muñoz y colaboradores (1997), retomando el tema, piensan que en esta interacción cultural fueron actores durante la época prehispánica, las poblaciones denominadas Cultura de Arica y las pertenecientes a los Reinos Post-Tiwanaku, quienes habrían coexistido en una primera fase en un esquema de armonía social para posteriormente pasar a períodos de conflictos. Ellos acotan que del análisis de las evidencias arqueológicas y etnohistóricas se desprende que a partir del segundo milenio d.C., en estos Valles Occidentales el poblamiento humano fue pluriétnico, coexistiendo poblaciones de origen costero-valluno y serrano (precordilleranos); esta situación se habría producido como consecuencia del aprovechamiento de los recursos naturales y de la explotación de la tierra bajo dos mecanismos: el de la complementariedad económica de tipo vertical, organizado fundamentalmente por las poblaciones serranas con el propósito de dominar las tierras bajas del Pacífico, y el de complementariedad horizontal, en el cual poblaciones vallunas y costeras explotaban simultáneamente diversos valles y quebradas en los valles occidentales.

Por su parte, Durston e Hidalgo (1997) comentan que la etnohistoria de Arica se ha planteado por 
largo tiempo desde la perspectiva de la complementariedad ecológica. Concretamente, se ha buscado explicar los perfiles demográficos, socioeconómicos y políticos de las poblaciones étnicas de la zona, en términos de prácticas de acceso directo por medio de "archipiélagos verticales", siguiendo el modelo propuesto por Murra. Como hipótesis general proponen que los archipiélagos serranos (precordilleranos) conocidos por la documentación del siglo XVIII son archipiélagos "nuevos", que aparecen con la consolidación del cacicazgo de Codpa como unidad política que cobija los nuevos núcleos, los pueblos serranos. Estos pueblos lograrían construir archipiélagos propios en un proceso que se extendería desde mediados del siglo XVII y que culminaría un siglo más tarde.

Santoro y colaboradores (2004) identifican arqueológicamente a los serranos como una unidad cultural que denominan Charcollo; al mismo tiempo, plantean sus dudas respecto al rol que jugaron estas poblaciones en el contexto macrorregional. No sabemos, dicen, si las instalaciones de la sierra (precordillera) corresponden a los centros secundarios dependientes de los centros primarios del altiplano, en el modelo de verticalidad escalonada propuesto por Durston e Hidalgo (1994); a lo que agregan, tampoco se sabe si controlaron, en su propio beneficio, el acceso de los andinos a la costa, donde se ubicarían los centros terciarios.

Como se aprecia, existe consenso de que al menos en la zona de Arica habría sido una realidad el fenómeno de verticalidad archipielágica, aunque cada autor lo visualiza con diferentes enfoques, tanto en el tiempo en que estas formaciones ocurrieron como en la forma en que estas se manifestaron. Tal vez la postura que ha tomado más fuerza ha sido interpretar la coexistencia de diversos tipos de alfarería en los sitios arqueológicos como evidencia de multi o plurietnicidad y ésta, a su vez, asumirla como expresión de verticalidad archipielágica.

Nuestra propuesta surge de una diferente lectura de la documentación arqueológica del norte de Chile (desde la frontera con Perú hasta el Salar de Atacama) (Figura 1) y trata de formular un proceso diacrónico, que aquí hemos designado como episodios, con la intención de dar un ordenamiento secuencial a los datos que entregan la arqueología y la etnohistoria, los que muchas veces aparecen entreverados en los contextos arqueológicos, por un lado, y por quienes escribieron los documentos del contacto europeo, por el otro.

\section{Primer Episodio: Complejización Sociopolítica de los Valles Occidentales}

Paralelo al desenvolvimiento de las poblaciones del sector bajo y de la costa de los Valles Occidentales (Focacci 1997; Muñoz 1979; Schiappacasse et al. 1989), en la precordillera, a alturas entre $2.500 \mathrm{y}$ 3.500 msm (1730' S-1900' S), también había gente ocupando accidentados parajes y acomodándose a las abruptas quebradas donde se generan los ríos tributarios que drenan por la sierra de Huaylillas hacia los valles de Lluta, Azapa, Vitor y Camarones (Espoueys et al. 1994; Muñoz y Chacama 2006; Muñoz et al. 1987; Muñoz et al. 1997; Niemeyer y Schiappacasse 1981; Niemeyer et al. 1972-73). Estas ocupaciones tuvieron su emergencia en el Período Medio (ca. 500 a 1.000 d.C.), de tal manera que a finales de ese período ya había gente viviendo en las cabeceras de los grandes valles, destacando entre las más tempranas Pujone, en el área de Chapiquiña, y Miñi Miñi y Miñita en la quebrada de Miñita (Muñoz y Chacama 2006). Estas poblaciones precordilleranas corresponderían a lo que Santoro y colaboradores han definido como grupo Charcollo (Santoro et al. 2004).

El atractivo para vivir en este piso altitudinal (entre 2.500 y $3.500 \mathrm{msm}$ ), de rigurosas condiciones comparadas con las de los valles bajos, era la posibilidad de criar ganado. Estas poblaciones tenían una raigambre pastoril que venía de generaciones anteriores, y aquí las condiciones ambientales eran especialmente favorables para la multiplicación de los camélidos. A esto se sumaba el hecho que, precisamente en esta franja altitudinal, se daba también la posibilidad de cultivar productos de media altura, incluyendo maíz. En consecuencia, en estos recovecos precordilleranos se podía desarrollar una economía mixta, obteniendo una complementación ideal entre recursos cárneos y vegetales.

Es así que en las quebradas de Socoroma, Copaquilla, Chapiquiña, Livilcar, Belén, Ticnamar, Cobija, Codpa, Miñita y Camarones alto se llegaron a instalar a lo menos 25 importantes poblados (Muñoz y Chacama 2006).

Entre estas poblaciones de altura y las de los valles bajos inicialmente se habría establecido un sistema de interacción que arqueológicamente ha quedado registrado por el cruce de las cerámicas: presencia de cerámica San Miguel, Pocoma y Gentilar en las tierras altas y cerámica Chilpe y Charcollo en las tierras bajas. Detrás de este trasvasije artefactual 


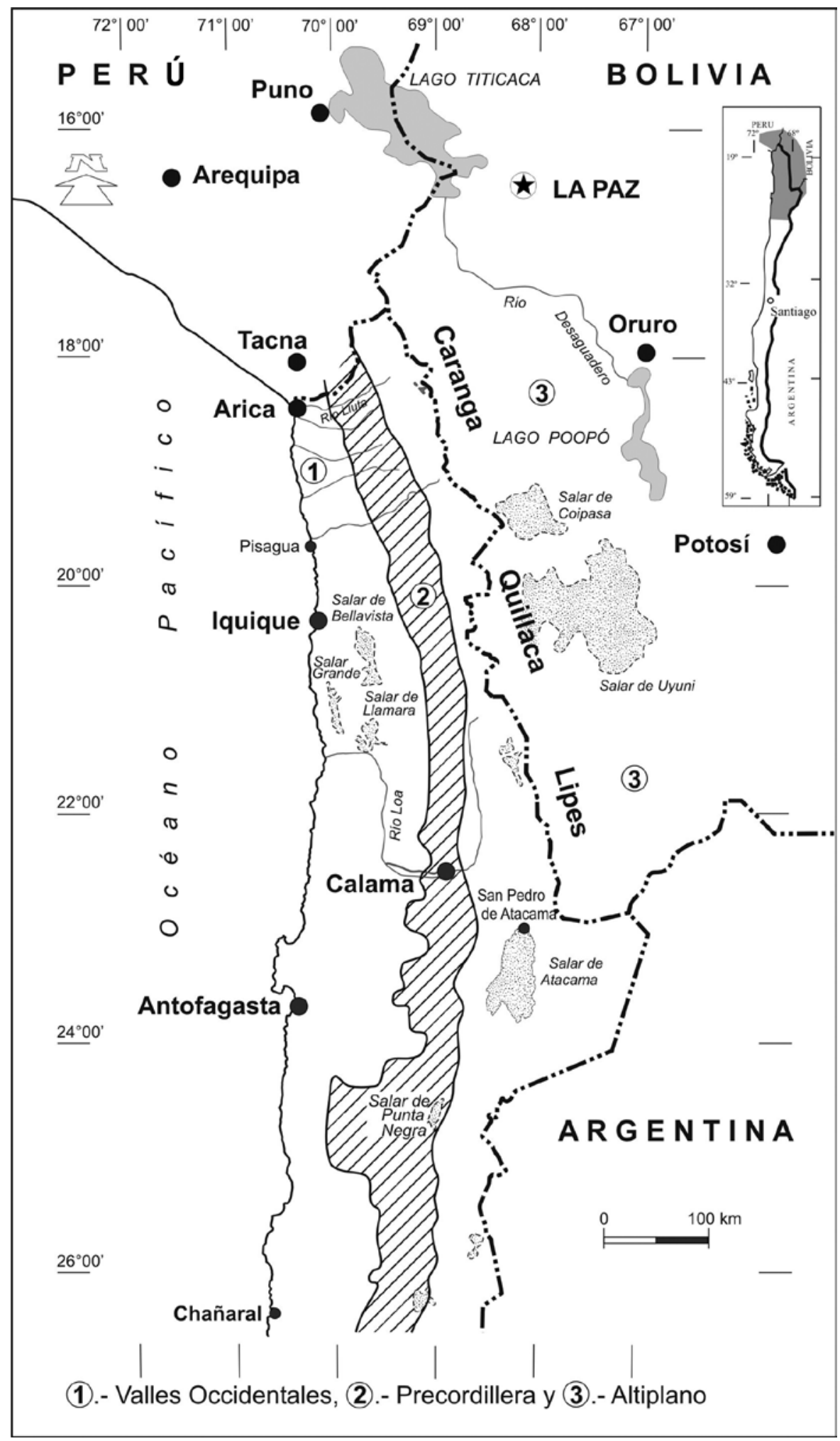

Figura 1. Área geográfica referida en el texto.

The geographic area referenced in the text. 
se revela algo mucho más substancial que un simple intercambio de objetos: una necesidad sentida de complementación de recursos.

La forma de resolver la digresión ecológica entre valles altos y valles bajos, para estas poblaciones, parece haber sido el establecimiento de un sistema de "integración complementaria" llevado a cabo a través de una articulación político-social de las poblaciones "de arriba" con las poblaciones "de abajo", sustentada en la premisa de intercambio de bienes y productos y normada fundamentalmente por principios de reciprocidad y redistribución complementaria. Es interesante considerar, por ejemplo, que en los sitios de Playa Miller, a pesar de poseer tejidos en sus contextos, no se encuentran los instrumentos para tejer ni los telares, los que son frecuentes en las sepulturas de los valles (Focacci 1997); seguramente, esto significa que los grupos costeños obtenían los tejidos por canje con los agricultores y ganaderos del valle y/o de la precordillera a cambio de productos marinos. Algo similar se plantea para la costa tarapaqueña:

esta ocupación de la costa coexiste e interactúa con los desarrollos de los valles interiores, pero no necesariamente corresponde a enclaves vallunos o 'colonias'. Más bien parece que el movimiento de ciertos bienes presentes en la costa, como los tejidos tan reparados y reutilizados, son manejados desde el interior sobre la base de intercambio (Agüero 2007:132).

Postulamos que en este primer episodio no se trataría de "verticalidad", entendida ésta como acceso directo a distintos pisos ecológicos por miembros de una misma comunidad (Murra 1975; Salomon 1985), sino una complementariedad articulada entre comunidades distintas. Un complejo sistema de interacción en que cada entidad mantuvo control especializado sobre los recursos de su correspondiente piso ecológico, lo que, para que funcionara óptima y eficientemente, tuvo que tener sus implicancias políticas. Santoro y colaboradores postulan al grupo serrano separado de la esfera política y cultural de los de Arica y más relacionado a la esfera altiplánica (Santoro et al. 2004). Pero, por otro lado, se dice que el flujo genético entre los "de arriba" y los "de abajo", aunque disminuye en el Intermedio Tardío en relación al período Medio, se mantiene activo (Rothhammer y Santoro 2001), lo que hace ver que a pesar de tratarse de poblaciones diferentes persiste una interacción que involucraría, incluso, vínculos de intercambio genético (matrimoniales). Esto respalda la idea de dos comunidades distintas, pero que, a nivel de relaciones de entidades interactuantes, tuvieron que formalizar sus protocolos de relaciones mutuas y consolidar el mando político en dos polos formales de interlocución: uno en las tierras bajas, probablemente en San Lorenzo, y otro en las tierras altas, posiblemente en Pubriza y/o en Huaihuarani. Por qué no pensar que ambos liderazgos podrían haber llegado a hacer parte de un co-gobierno integrado (compartido), adscribiéndose a una estructura similar a la conocida en antropología como "dualidad".

\section{Segundo Episodio: Frontera de la Discordia y Pukaras}

Mientras al lado occidental de la Cordillera de los Andes (17 $30^{\prime}$ S-1900' S) estaba teniendo lugar el desarrollo al que nos hemos referido, con sociedades que eficientemente se habrían organizado en el ámbito regional desde la costa hasta la precordillera (ver Santoro et al. 2004), al otro lado de la cordillera, en el altiplano, había una numerosa población de pastores, que en su momento había estado fuertemente vinculada a Tiwanaku, pero que, ante el colapso de esta entidad, se encontró carente del soporte de la macro zred interactiva que les permitía abastecerse de los productos complementarios de las tierras bajas, al tiempo que sufría las inclemencias ambientales que flagelaban las tierras altas y mermaban su potencial productivo. Cuando cayó Tiwanaku, los cimientos todos de la sociedad surandina se estremecieron y la superestructura de articulación quedó afectada a niveles irreversibles. Un sistema monumental orquestado por un poder central, que llevó 500 años perfeccionar, organizar y armonizar, era muy difícil de ser recuperado en el fragmentado y desarticulado panorama postiwanaku (ca. 1.000 a 1.300 d.C).

Las numerosas fortalezas o pukaras que se construyeron en ese tiempo nos hacen ver que se ha creado un clima de conflicto sin precedente (Nielsen 2007). Estas fortalezas emergieron en el borde del altiplano y de la puna, en ambos flancos cordilleranos, desde el sur de Perú y sur de Bolivia hasta el norte de Chile y noroeste de Argentina, situación que refrenda lo generalizado de los conflictos derivados de la caída de Tiwanaku. Si hubo 
un período de intensa sequía (Thompson et al. 1985), podemos pensar que las poblaciones mayormente afectadas por este fenómeno fueron precisamente las del altiplano y las de la puna. Las populosas poblaciones pastoriles allí residentes vieron, por un lado, resentido su propio sistema productivo y, por otro, no lograban obtener cobertura para sus necesidades de productos agrícolas a través del flujo complementario, ya que las poblaciones horticultoras no podían producir suficientes excedentes para integrarlos al flujo que, por lo demás, estaba desarticulado. Frente a esto y frente a la intransable necesidad de complementación, algunos grupos altiplánicos habrían optado por una modalidad de incursiones de rapiña sobre las poblaciones horticultoras precordilleranas para apoderarse de sus cosechas. El maíz pudo haber sido el principal motivo de los enfrentamientos, ya que se había convertido en un valioso y apetecido recurso debido a su alto valor dietético y ceremonial, producto que había que obtener, por un lado, y defender, por el otro, a cualquier costo.

Estos grupos altiplánicos alzados organizaban ataques, probablemente en épocas de cosecha, los que al parecer ya se iniciaron en tiempos de las poblaciones San Miguel, por lo cual estas se vieron obligadas a fortificar el poblado de San Lorenzo. Estas campañas marcaron la tónica del período que nos ocupa (ca. 1.000 a 1.300 d.C.), de tal manera que las aldeas de la precordillera tuvieron que adoptar medidas defensivas contra los atacantes altiplánicos.

En la mayoría de los casos, las propias aldeas preexistentes fueron fortificadas, desplazando su crecimiento hacia sectores más elevados, aislando esta parte con la construcción de muros defensivos e instalando en su interior los almacenes donde guardaban las cosechas, ya que esto era lo que había que defender con mayor ahínco. En otros casos se construía el pukara separado de la aldea, en algún promontorio o ladera estratégicamente situada, agregándole muros perimetrales para acentuar sus condiciones de protección. Sin duda, la gente que normalmente vivía en los sectores bajos del valle, en los momentos de tensión, se refugiaba y defendía desde ahí.

Es posible que las acciones bélicas inicialmente se dieron en forma intermitente, a manera de escaramuzas; pero, en la medida que los grupos de pastores altiplánicos se fueron organizando y cohesionando en torno a estas incursiones, pudieron poner en práctica un plan estratégico no sólo para apropiarse de las cosechas sino del propio territorio productivo precordillerano, el que ya a esas alturas se había convertido en aspiración de complementariedad para ellos. En consecuencia, los altiplánicos de la región lacustre (Desaguadero-Poopó, Figura 1), habrían llegado, finalmente, a ocupar la franja precordillerana, apropiándose de los asentamientos preexistentes y también estableciendo nuevos asentamientos.

El hecho de no encontrar cerámica altiplánica en cantidades significativas en los asentamientos de los valles bajos indicaría que los altiplánicos no lograron o no quisieron incursionar más abajo de la sierra Huaylillas; por otro lado, dado el clima de tensión, es probable que en este episodio no hubiera mayor interacción entre las poblaciones de las tierras bajas y los invasores.

Replicando la situación del norte, al interior de Iquique (1900' S-21 $1^{\circ} 23^{\prime} \mathrm{S}$ ) también encontramos gente ocupando la precordillera y adaptando sus asentamientos al relieve quebradeño; igualmente, como en el interior de Arica debieron poner en práctica un complejo sistema de canales y acequias para poder llevar agua hasta los huertos aterrazados. Aprovechando este ambiente de altura, esta gente propició, además, la crianza de ganado de llamas y alpacas. Se establecieron en las cabeceras de las quebradas, entre 2.000 y $3.500 \mathrm{msm}$, ocupando especialmente Mocha, Chusmiza, Guaviña, Sibaya y Chiapa.

Seguramente estas poblaciones "de arriba" también se articularon complementariamente con las "de abajo", identificadas estas últimas con el Complejo Cultural Pica-Tarapacá (Uribe 2006). Estos mecanismos de complementariedad deben haber estado enmarcados en una estructura geopolítica en la que el aspecto superficial y explícito era el intercambio o trueque de productos, pero detrás de ello, existía una estructura política de gobierno compartido, formalizada a través de lo que se ha visto como "dualidad".

En su momento, esta zona precordillerana fue escenario del mismo proceso descrito para el norte. Poblaciones pastoriles transandinas afectadas por el estrés post-Tiwanaku se dedicaron a hostilizar a los tarapaqueños para apropiarse de su producción y de sus tierras agrícolas. Las incursiones de rapiña de la gente de las alturas se hicieron sentir tan abajo como en la pampa del Tamarugal, siendo así que los habitantes de Caserones tuvieron que 
amurallar su aldea para protegerse de los agresores (Núñez 1982).

Estas poblaciones alzadas tuvieron un origen diferente de aquellas del norte; ellas estaban más bien relacionadas con el área de los grandes salares de Coipasa y Uyuni, situadas en el altiplano y colindantes al territorio tarapaqueño meridional. Bajo esta presión, los pobladores de las quebradas precordilleranas reaccionaron de idéntica forma a como lo hicieron los del norte: atrincherándose en lugares estratégicos y erigiendo fortalezas como los pukaras de Pukar Qollu (Isluga), de Chusmisa, de Mocha, de Nama, de Carora y de Jamajuga o Cerro Gentilar (Núñez 1983; Moragas 1991).

Se plantea que durante la segunda mitad del Período Intermedio Tardío del territorio PicaTarapacá (Fase Camiña) se habrían perdido los circuitos de interacción del momento anterior, ocupándose en forma intensa los cursos medios $\mathrm{y}$ altos de las quebradas donde se hace presente fuertemente un componente altiplánico (Agüero 2007; Uribe et al. 2007).

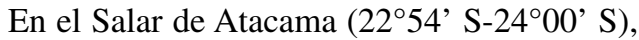
en el Período Medio, los oasis habían sido propicios para el desarrollo de un núcleo poblacional de considerable masa crítica con una situación sociopolítica sólida (Berenguer y Dauelsberg 1989; Uribe y Agüero 2001); en tanto, la cuenca del río Loa estaba ocupada por comunidades pequeñas, dispersas y laxamente organizadas, al punto que escasamente lograron articularse con el macrosistema potenciado por Tiwanaku.

Poco a poco las tierras altas de la cuenca del río Loa, especialmente del río Salado, fueron siendo ocupadas por flujos poblacionales procedentes del altiplano. Esta gente, aprovechando el vacío a este lado de la cordillera y presionada por la progresiva sequía, se fueron asentando en lugares fértiles de la precordillera, llegando a consolidar aldeas conglomeradas como Toconce y Turi. Esta población pertenecía a lo que se ha llamado Tradición Altiplánica (Aldunate 1991; Aldunate y Castro 1981; Schiappacasse et al. 1989), la que fluyó especialmente hacia la precordillera y las quebradas altas del río Salado, siendo el poblado de Likán, en el valle de Toconce, el más fiel representante de esta tradición.

Presumiblemente, el asentamiento de Likán habría sido dependiente de alguna entidad mayor que situaba su cabecera política en la zona norte de Lipes (actual sur de Bolivia). Esta entidad, eminentemente pastoril, por ubicarse en el altiplano estaba afecta a las limitaciones propias de la altura para cultivar ninguna otra cosa que no fueran quínoa y tubérculos, siendo, en consecuencia, indispensable para su población disponer de un enclave en territorio de menor altura, donde fuese factible cultivar especialmente maíz. Para esos fines habrían implantado la aldea de Likán en el valle de Toconce, implementada con extensas andenerías de cultivo y canales de regadío.

A su vez, $20 \mathrm{~km}$ más abajo de Likán, había gente de raigambre más local, la que se hallaba ocupando el alto Loa, quebradas intermedias y lugares habitables en el cauce bajo de dicho río; a ellas se las identifica con la Tradición del Desierto o Tradición Atacameña (Aldunate 1991; Aldunate et al. 1986). En la precordillera, esta población se había asentado en la gran vega de Turi, la que alimentada por aguas subterráneas era la única fuente permanente de pastos en la región. Allí se establecieron en el poblado de Turi, que más tarde llegó a constituirse en pukara (Aldunate 1991); a éste se suman asentamientos en el curso medio de la cuenca del Loa, tales como Caspana, Lasana, Chiu Chiu, Calama, Chacance y Quillagua. Sin duda, Turi fue el principal centro proveedor de ganado para los pueblos de más baja altitud y éstos, a su vez, de productos agrícolas para la población de Turi; una vez más nos encontramos frente al esquema de los "de abajo" y los "de arriba". Inicialmente, también pudo haber una relación armónica y complementaria entre Turi y Likán dada su proximidad.

Pero, al igual que en el norte y en los mismos momentos, las poblaciones altiplánicas estaban empeñadas en tener acceso a los productos agropecuarios de las quebradas occidentales. Siendo Turi frontera entre los altiplánicos y los atacameños, se convirtió en el principal escenario de enfrentamientos. Es así que al igual que todas las comunidades precordilleranas las de Turi debieron tomar providencias para defenderse $y$, junto con ello, constituirse en un frente para cerrar el paso y proteger a los agricultores de los valles bajos. Sus habitantes tuvieron que construir un monumental muro perimetral para circundar defensivamente el asentamiento, con lo cual este poblado se convirtió en pukara.

Parece ser que finalmente los altiplánicos de Lipes lograron tomar la fortaleza de Turi y desde allí intentaron continuar su avance hacia las tierras 
bajas, por lo cual los atacameños tuvieron que establecer un segundo frente de resistencia con los pukaras de Lasana y de Chiu Chiu. La intromisión altiplánica en Turi quedó plasmada en la construcción de chullpas, en las modificaciones de su arquitectura, en el considerable aumento de tamaño y en la intensidad de la ocupación (Aldunate 1991; Aldunate et al. 1979; Castro et al. 1991).

Al parecer, la gente de la Tradición Altiplánica no logró instalarse en el Salar de Atacama ya que prácticamente toda la cuenca desde antes estaba ocupada por comunidades de la Tradición del Desierto o Atacameña (Llagostera 2004). Sin embargo, en algún momento de este período los atacameños del salar, al igual que los pueblos del norte, tuvieron que tomar medidas defensivas contra los altoandinos, las que se concretaron en la construcción del Pukara de Quitor y otros de menor envergadura como el de Vilama, el de Oyrintur, el de Alto del Abra y el de Tchapuraqui. Complementariamente se registra, en los cementerios de la época, que un tercio de la población presenta huellas de traumas y heridas recibidas en enfrentamientos, situación que afectaba tanto a hombres como a mujeres (TorresRouff et al. 2005).

Los primeros momentos postiwanaku en la región atacameña han sido descritos por los arqueólogos como de un "empobrecimiento" cultural, debido a que los ajuares funerarios son exiguos, con pocos objetos y de menor calidad en relación a la época anterior; en muchos casos, los tiestos de greda fueron reemplazados por calabazas $\mathrm{y}$, en los cementerios de esta época, hay un gran número de tumbas que ni siquiera tienen ajuar. Creemos que este empobrecimiento cultural no refleja una decadencia cultural sino un momento de reestructuración sociopolítica de la etnia. La necesidad de respuestas masivas para hacer frente a los ataques obligó a la comunidad a cohesionarse y a redefinir los mandos étnicos, imponiendo como nueva cualidad para los líderes el dominio de estrategias bélicas. Se hizo necesario instaurar una diligencia corporativa en manos de estrategas guerreros más que en líderes chamánicos y no había tiempo para la elaboración de sofisticadas manufacturas.

Es posible que el convulsionado ambiente que venía afectando a la región incentivó a los atacameños del salar y del Loa medio a consolidar una alianza entre sus cabeceras administrativas: San Pedro de Atacama por un lado y Lasana-Chiu
Chiu por el otro. Alianza que se habría concretado en la estructuración de dos parcialidades, las que serán conocidas como Atacama La Alta y Atacama La Baja. Con esto la etnia atacameña alcanzó su mayor complejidad sociopolítica y su más extensa y definida circunscripción territorial, constituyéndose en el gran Señorío Atacameño.

\section{Tercer Episodio: Reestructuración Altiplánica y Archipiélagos Étnicos}

Para comprender los acontecimientos que tuvieron lugar en la prehistoria tardía del norte de lo que hoy es territorio chileno, debemos trasladarnos al otro lado de la cordillera andina, en lo que hoy es el suroeste de Bolivia ( $17^{\circ} 32^{\prime}$ S- $22^{\circ} 51^{\prime}$ $\mathrm{S}$, Figura 1) y centrarnos en aquellas poblaciones pastoriles del altiplano que, al quedar desvinculadas del macro sistema redistributivo por el colapso de Tiwanaku, tuvieron que reestructurarse, después de pasar por una etapa previa de pillaje sobre los agricultores de los valles precordilleranos (ca. 1.300 a 1.450 d.C.).

La documentación de principios de la invasión europea nos narra que estas poblaciones llegaron a instaurar una forma de organización geopolítica que Murra interpretó como "archipiélago vertical" o "archipiélago étnico" (Murra 1975). Este sistema archipielágico fue implementado por poblaciones del territorio Titicaca-Desaguadero-Poopó, etnias conocidas como Lupaca, Pacaje, Caranga y Quillaca, las que llegaron a consolidar estructuras socio-políticas de tal complejidad que han sido calificadas como Reinos o Señoríos Altiplánicos. De éstos, el que nos interesa directamente es el de los Caranga, ya que su territorio se explayaba entre el lago Poopó por el oriente y la Cordillera Occidental, por tanto, eran los vecinos inmediatos a los valles de Tarapacá.

Los enclaves que los altiplánicos obtuvieron en los valles precordilleranos de Tarapacá, como resultado de las guerras postiwanaku, les dieron estabilidad y los obligó a organizarse para no sólo seguir manteniendo las instalaciones usurpadas a los habitantes originarios, sino para expandir las tierras cultivables a través de nuevas construcciones de andenerías y de extensos canales. Para esta gente, la nueva situación de transitar de un régimen pastoril atomizado a otro muy diferente, de aglutinamiento en grandes poblados con nuevas responsabilidades comunitarias y haciéndose cargo 
de una economía mixta, inevitablemente los indujo a un replanteamiento socio-político, fortaleciendo la estructura de mando de tal manera que sus líderes fueran capaces de mantener la cohesión interna, al tiempo de proteger los espacios conquistados.

Los primeros invasores que ocuparon la precordillera tarapaqueña no se desvincularon de sus centros altiplánicos originarios; por el contrario, estructuraron mecanismos de articulación con el centro, constituyéndose como "islas" de un sistema archipielágico. Esto es, una cabecera políticoadministrativa en pleno altiplano, donde residía el señor principal, y enclaves en los valles occidentales, desde donde fluía la producción agrícola hacia el centro, en el cual, a su vez, se había reforzado la producción ganadera. Con esto, los altiplánicos lograron su aspiración de complementariedad y autosuficiencia, evolucionando rápidamente hacia niveles de mayor complejidad, que finalmente los va a consolidar como el Señorío Caranga (Barragán 1994). La documentación etnohistórica no deja dudas de que los Caranga establecieron enclaves en diversos puntos de la precordillera ariqueña (Durston e Hidalgo 1997; Santoro et al. 1987).

Otras poblaciones altiplánicas de nuestro interés, por colindar con el sur de Tarapacá y con el norte de la precordillera de Antofagasta, son los Quillaca y los Lipes (Espinoza 1981; Fernández 1978; Martínez 1991). Los primeros se desplegaban entre los grandes salares de Coipasa y Uyuni. Por su parte, los segundos se ubicaban en el borde occidental de lo que hoy es el sur de Bolivia, desde el salar de Uyuni hasta la naciente de la cuenca del río Quetena (Figura 1).

Los Quillaca y los Lipes, comparados con los Carangas, aparecen como poblaciones bastante más disminuidas en lo social, político y económico, dado que su densidad demográfica era menor y estaban asentados en la Puna Salada, territorio mucho más inhóspito. Estos factores deben haber incidido en una estructura política laxa que no logró concentración en poblados mayores ni tampoco evolucionar hacia un verdadero "señorío". Según parece, ambas entidades estaban conformadas por varios grupos étnicos aglutinados bajo un sistema de confederación, sin una estructura piramidal de jerarquías centralizadas. Sin embargo, aunque a menor escala, lograron instaurar sistemas archipielágicos hacia el lado occidental de la cordillera, siendo éstos los más meridionales de tales sistemas, con Turi como la "isla" más extrema.

\section{Cuarto Episodio: Integración Supraétnica}

Cuando las nacientes de los valles y oasis occidentales se encontraban prácticamente en poder de los pastores altiplánicos, un nuevo episodio vino a incidir en este proceso, el que se relaciona directamente con el proyecto expansionista del Imperio Inka (ca. 1.450 a 1.500 d.C.). Dado que la primera anexión al poder centralizador del Cusco fue la región altiplánica y que las cabeceras de los Valles Occidentales mantenían estrechos vínculos con aquella región a través del fenómeno de los "archipiélagos étnicos", la corriente inkaica llegó a esos valles con anterioridad a la propia ola expansionista cuzqueña. De esta manera, al llegar las huestes conquistadoras enviadas desde el Cusco, se encontraron con una región inkanizada puesto que, de antes ya, estaba incorporada al Complejo Inka Altiplánico (Llagostera 1976).

En una primera instancia, el poder central del Cusco no ejerció dominio directo sobre los actuales valles y oasis del norte de Chile. No era una región de utilidad inmediata para la gran empresa Inka, ya que la producción agropecuaria local no era diferente ni potencialmente necesaria para la política expansionista del Tawantinsuyo. Por otro lado, con la anexión Inka del territorio altiplánico que dio origen al Kollasuyo, inmediatamente comenzó la aculturación inkanizante de sus pobladores, ya que los señoríos altiplánicos, entre ellos los señoríos Caranga y Quillaca, y tal vez los Lipes, con sus "islas" occidentales, quedaron incorporados al Imperio. Por consiguiente, la presencia Inka en tierras tarapaqueñas fue una situación mediatizada, inherente al nexo isla-núcleo de los archipiélagos étnicos, ya que en este momento los habitantes de los poblados precordilleranos de los valles tarapaqueños hacían parte de un mismo universo con los del núcleo Caranga, lo cual es confirmado por los antecedentes documentales del siglo XVI (Durston e Hidalgo 1997:252).

En consecuencia, cuando el avance inkaico llegó a la región septentrional del actual norte de Chile se encontraron con una región ya inkanizada, donde había "colonias inkaicas" y, además, etnias locales habituadas a su presencia. Una conquista allí no tenía sentido. Solamente se justificaba continuar implementando la infraestructura vial, que facilitara los avances expansionistas hacia el sur, siendo en este rubro donde los cuzqueños pudieron haber intervenido directamente. 
En consecuencia, el posicionamiento inkaico de los Valles Occidentales del extremo norte de Chile, entendiendo por ello la integración de esta zona al Tawantinsuyo, se concretó a través del señorío Caranga y, en un primer momento, estuvo limitada a la precordillera. Posiblemente, más tarde, frente al nuevo panorama político, se produjo un ablandamiento de la conflictiva frontera precordillerana, reabriéndose la interacción entre los "de abajo" y los "de arriba" (ahora altiplánicos), con lo cual la inkanización fue filtrando hacia las tierras bajas. Es posible que los propios vallunos hayan ansiado esta apertura para volver a tener acceso a los codiciados camélidos, recurso que se había restringido cuando los altiplánicos se apoderaron de los valles altos.

De alguna manera, los poblados precordilleranos sirvieron de biombo, por lo cual los Inka no interactuaron directamente con las poblaciones costeñas; por lo menos, no en los primeros momentos. No se conoce la existencia de poblados de la Cultura Arica reocupados por los Inka y, mucho menos, un sincretismo entre la cerámica Gentilar y la inkaica. En todo caso, al parecer, no hubo oposición de parte de los gentilares para interactuar con los grupos inkanizados, ya que con la desvinculación de los reductos precordilleranos durante el período de conflictos, tienen que haber resentido seriamente su complementariedad y estaban ansiosos de recuperarla. Covey observa que para el sur de Perú los Inka no efectuaron su desarrollo imperial de la costa o no quisieron incorporar grupos costeros directamente; señala que es posible que los kurakas locales mantuvieron sus propias opciones en sus interacciones con el Tawantinsuyo (Covey 2000).

Los intereses de los Inka en esta región fueron coincidentes con los de los Caranga, en cuanto a optimizar la producción agropecuaria de la zona, para lograr un adecuado abastecimiento hortícola hacia las poblaciones altiplánicas y, más todavía, tener acceso a los productos marinos. No nos olvidemos que los señores Caranga eran ahora, a su vez, jerarcas inkaicos y, sin duda, su principal preocupación era el buen funcionamiento de su "archipiélago étnico". En vista de ello, se continuaron ampliando los terrenos cultivables de las "islas" precordilleranas y mejorando la infraestructura hidráulica para satisfacer las necesidades locales y estatales, lo que incluyó canales de trasvasije entre valles (Santoro et al. 1987).

\section{Consideraciones Finales}

A excepción de Osmore en Perú, no hay claridad de que hayan existido otras colonias tiwanaku en la vertiente andina occidental. La presencia de artefactos tiwanakotas en sitios de esta vertiente la interpretamos a través de lo que estamos llamando "Sistema Reticular de Interacción Puneña". Prácticamente desde tiempos anteriores al Período Medio ya habría quedado estructurado un patrón de interacción y complementariedad sui generis, el que no sólo conllevaba objetivos ecológicos y de consumo, sino también objetivos sociales y políticos, donde el traslado de objetos y de personas era la parte tangible de una compleja articulación que integraba a las poblaciones puneñas en una macroentidad solidaria y complementaria, bajo cánones compartidos y ritualizados (Llagostera 1996, 2006). Fluyendo por este entramado, los objetos podían desplazarse a largas distancias sin que necesariamente hubiera interacción directa entre el grupo que los produce y el que los recibe; asimismo, a través de esta malla, cada nodo podía acceder a bienes y productos de diversos orígenes.

La participación corporativa y solidaria de los diversos pueblos en el flujo reticular de intercambio y reciprocidad era de tal eficiencia que habría sido utilizado y perfeccionado por Tiwanaku, especialmente a través de fortalecer los mandos locales de las etnias para reorientarlo en función de los intereses estatales. Con esto se dio una mayor cobertura y diversidad a la complementariedad, respondiendo así a los intereses que por siglos habían sido los propios intereses del mosaico étnico puneño y circumpuneño. Este sistema no sólo implicaba movimiento de gente transportando bienes y productos, sino también gente que cambiaba su residencia de un nodo a otro mediante nexos matrimoniales. De esta forma, la interacción entre los nodos quedaba comprometida a través de lazos de parentesco político, como mecanismo de sustento de la propia red, tanto a nivel de enlace con territorios y productos lejanos como para que el complejo sistema de prestigio no decayera. En consecuencia, postulamos que la necesidad de complementariedad en el Período Medio fue resuelta a través de este sistema y no necesariamente a través del implante de colonias como ha sido sugerido por otros autores (Berenguer 1998; Oakland 1992; Ponce 1972).

Para finales del Período Medio e inicios del Intermedio Tardío (ca. 800 a 1.100 d.C.), tanto en 
la costa como en la precordillera de Arica, había poblaciones con suficiente densidad demográfica y manejo de sus respectivos nichos ecológicos como para buscar mecanismos formales de integración sociopolítica, de manera que, sin perder sus correspondientes identidades étnicas, les permitieran consolidar alianzas de complementariedad entre sí. Bajo este esquema no cabe la figura de archipiélago étnico, ya que las parcialidades de los valles bajos y las de valles altos o cabeceras de valles han tenido sus propias génesis, constituyéndose en entidades maduras, cada una caracterizada arqueológicamente por una ergología que las identifica y las diferencia de sus vecinas.

En el Intermedio Tardío (ca. 1.000-1.450 d.C.) se conjugaron acontecimientos sociopolíticos y eventos medioambientales que motivaron una reestructuración sin precedente en las tierras altoandinas. Ante la sequía y la consecuente desintegración de Tiwanaku, las poblaciones altiplánicas se habrían visto forzadas a obtener por la fuerza los productos hortícolas producidos por los habitantes de la precordillera (sierra o prepuna), los que antes eran obtenidos a través del macrosistema de interacción orquestado por Tiwanaku. Frente a esta agresión, las poblaciones precordilleranas del interior de Arica y zona tarapaqueña, que hacían parte complementaria y dual del complejo valluno, debieron tomar medidas defensivas, fortificando sus reductos a manera de fortalezas (pukaras). Al parecer, estos reductos cayeron finalmente en poder de las poblaciones altiplánicas, con lo cual recién se habría consolidado la estructura de archipiélago vertical o étnico, en los términos de Murra.

Estas estructuras contemplaban una cabecera político-administrativa en pleno altiplano (hoy boliviano), donde residía el señor principal, y enclaves en las nacientes de los Valles Occidentales tarapaqueños y atacameños (alto Loa). De esta forma se habría producido la emergencia de los sistemas archipielágicos más meridionales. Estos sistemas fueron implementados principalmente por poblaciones del territorio Desaguadero-Poopó e intersalares, etnias conocidas como Caranga, Quillaca y también Lipes. En consecuencia, al menos en la vertiente occidental andina, el límite meridional de estas formaciones archipielágicas pareciera encontrarse a la latitud del río Loa, siendo Turi la expresión más sureña de los "archipiélagos verticales". Las poblaciones de la región del Salar de Atacama lograron resistir la agresión de los puneños, manteniendo el control de sus pukaras y de sus tierras; en consecuencia, esta región no fue incorporada como "isla étnica" a ningún sistema archipielágico que tuviera su cabecera en la puna o en el altiplano.

Estos sistemas archipielágicos que originalmente involucraron altiplano y cabeceras de los Valles Occidentales, con el dominio inkaico (ca. 1.450 a 1.500 d.C.) flexibilizaron la frontera serrana, abriéndose a los valles bajos. Sin duda, esta intromisión implicó una nueva reestructuración que, como plantea Hidalgo (1996), al menos en Arica, los reinos circunlacustres mantuvieron relaciones pluriétnicas en un esquema de verticalidad, bajo el paraguas inkaico que les impedía romper la paz entre sí; sin embargo, la población costera local debió aceptar una nueva clase de relación basada en el dominio foráneo de su gente y de sus recursos.

Otro aspecto que se relaciona con el tema de los archipiélagos étnicos es el de la multi o plurietnicidad. Murra señala que los asentamientos periféricos eran multiétnicos y hace un llamado diciendo que este carácter de las colonias marginales merece investigación arqueológica (Murra 1975). Frente a esto se ha asumido que la coexistencia en los sitios arqueológicos de alfarerías de diferentes filiaciones, es evidencia de multietnicidad y, en consecuencia, de sistemas archipielágicos.

Romero (2005) plantea que la distribución de referentes materiales, como la cerámica y la arquitectura en Huaihuarani, da cuenta de una ocupación conjunta de diferentes poblaciones. Reconoce una población local (precordillerana) junto a una población altiplánica, o en su defecto una población que mantuvo una mayor relación con los grupos altiplánicos, frente a lo cual agrega una situación prevista sólo parcialmente por el modelo original de Murra, que enfatiza la ocupación multiétnica de nichos o espacios y no de poblados o asentamientos propiamente tales. La observación de Romero es plenamente válida y nos lleva a marcar diferencias entre las islas que aquí estamos tratando y las de los Lupaca, etnia que fue la que dio base a Murra para su modelo. Estas diferencias, desde nuestro punto de vista, tienen que ver con la distinta gestación de las islas archipielágicas. A diferencia del pacífico proceso por el que pasaron los Lupaca para establecer enclaves en los valles, sin interferencia con las comunidades locales, las islas de los señoríos meridionales, según lo que estamos postulando, 
se habrían originado por un proceso bélico de apropiación de tierras cultivables, por parte de los altiplánicos, para lo cual tuvieron que doblegar a la población local precordillerana, tomando posesión de sus asentamientos. Finalmente, locales y foráneos tuvieron que haber llegado a transar una convivencia intramuros, la que se manifestaría arqueológicamente a través de la presencia de los distintos referentes materiales, delatando la convivencia de precordilleranos y altiplánicos en los mismos poblados.

Agradecimientos: Un especial agradecimiento al colega Juan Chacama por los recorridos de reconocimiento por la precordillera de Arica, los cuales fueron muy motivadores y aclaratorios. Asimismo, a los evaluadores por sus valiosos aportes y comentarios.

\section{Referencias Citadas}

Agüero, M.C.

2007 Acerca del Rol del Vestuario en el Surgimiento, Desarrollo y Consolidación del "Complejo Pica-Tarapacá" (Período Intermedio Tardio). Tesis para optar al Grado de Magíster en Antropología con mención en Arqueología. Universidad Católica del Norte/ Universidad de Tarapacá. San Pedro de Atacama.

Aldunate, $\mathrm{C}$.

1991 Arqueología en el Pukara de Turi. Actas del XII Congreso Nacional de Arqueología Chilena, Tomo 2, pp. 61-77.

Aldunate, C., J. Berenguer y V. Castro

1979 La función de las chullpa en Likán. Actas del VIII Congreso de Arqueología Chilena, pp. 129-174.

Aldunate, C., J. Berenguer, V. Castro, L. Cornejo, J.L. Martínez y C. Sinclaire

1986 Cronología y asentamiento en la región del Loa Superior. Dirección de Investigación y Bibliotecas-Universidad de Chile.

Aldunate, C. y V. Castro

1981 Las Chullpas de Toconce y su Relación con el Poblamiento Altiplánico en el Loa Superior, Período Tardío. Editorial Kultrún, Santiago.

Arellano, J. y E. Berberián

1981 Mallku, el señorío post-Tiwanaku del altiplano sur de Bolivia. Boletín del Instituto Francés de Estudios Andinos 10(1):51-84.

Barragán, R.

1994 ¿Indios de Arco y Flecha? Ediciones ASUR, Sucre.

Berenguer, J.

1998 La iconografía del poder en Tiwanaku y su rol en la integración de zonas de frontera. Boletín del Museo Chileno de Arte Precolombino 7:19-37.

Berenguer, J. y P. Dauelsberg

1989 El Norte Grande en la órbita de Tiwanaku. En Prehistoria, desde sus Orígenes hasta los Albores de la Conquista, editado por J. Hidalgo, V. Schiappacasse, H. Niemeyer, C. Aldunate e I. Solimano, pp. 129-180. Editorial Andrés Bello, Santiago.

Castro, V., F. Maldonado y M. Vásquez 1991 Arquitectura del Pukara de Turi. Actas del XII Congreso Nacional de Arqueología Chilena, Tomo 2, pp. 79-102.

Covey, A.

2000 Inka administration of the far South coast of Peru. Latin American Antiquity 11:119-138.
Durston, A. y J. Hidalgo

1997 La presencia andina en los valles de Arica, siglos XVI-XVIII: casos de regeneración colonial de estructuras archipielágicas. Chungara Revista de Antropología 29:249-273.

Espinoza, W.

1981 El reino aymara de Quillaca-Asanaque, siglos XV y XVI. Revista del Museo Nacional 45:175-274, Lima.

Espoueys, O., V. Schiappacasse, J. Berenguer y M. Uribe 1994 En torno al surgimiento de la Cultura Arica. Actas del XIII Congreso Nacional de Arqueología Chilena, Tomo 1, pp. 171-184.

Fernández, J.

1978 Los chichas, los lipes y un posible enclave de la cultura de San Pedro de Atacama en la zona limítrofe argentinoboliviana. Estudios Atacameños 6:19-35.

Focacci, G.

1997 Evidencias culturales andinas en registros arqueológicos Playa Millar-3. Diálogo Andino 16:101-122.

Llagostera, A.

1976 Hipótesis sobre la expansión incaica en la vertiente occidental de los Andes Meridionales. Anales de la Universidad del Norte 10:203-218.

1996 San Pedro de Atacama: Nodo de complementariedad reticular. En La Integración Surandina Cinco Siglos después. Estudios y Debates Regionales Andinos 91:17-42. Centro de Estudios Regionales Andinos "Bartolomé de Las Casas", Cusco.

2004 Los Antiguos Habitantes del Salar de Atacama, Prehistoria Atacameña. Pehuén Editores, Santiago.

2006 San Pedro de Atacama y el sistema reticular de interacción puneña. En Esferas de Interacción Prehistóricas y Fronteras Nacionales Modernas: los Andes Sur Centrales, editado por H. Lechtman, pp. 303-322. Historia andina 32. Instituto de Estudios Peruanos e Institute of Andean Research, Lima.

Martínez, J.L.

1991 Papeles distantes, palabras quebradas, las informaciones sobre Lipes en el siglo XVI. En Espacio, Etnias, Fronteras, Atenuaciones Políticas en el Sur del Tawantinsuyo, Siglos $X V$-XVIII, editado y compilado por A.M. Presta, pp. 285317. Ediciones ASUR. Sucre.

Moragas, C.

1991 Antecedentes sobre un pukara y estructura de cumbre asociada a un campo de geoglifos en la quebrada de 
Tarapacá, área de Mocha, I Región. Actas del XII Congreso de Arqueología Chilena, Tomo 2, pp. 25-39.

Mujica, E.J., M.A. Rivera y T.F. Lynch

1981 Proyecto de estudio sobre complementariedad económica Tiwanaku en los valles occidentales del centro-sur andino. Chungara 11:85-109.

Muñoz, I.R.

1979 Algunas consideraciones sobre el período del Desarrollo Regional de los valles bajos y costa de Arica. Actas del VIII Congreso de Arqueología Chilena, pp. 117-128.

2005 Espacio social y áreas de actividad en asentamientos agrícolas prehispánicos tardíos en la sierra de Arica. Bulletin de l'Institut Français d'Études Andines, 34(3):321-355.

Muñoz, I.R. y J.M. Chacama

2006 Complejidad Social en las Alturas de Arica: Territorio, Etnicidad y Vinculación con el Inca. Ediciones Universidad de Tarapacá, Arica

Muñoz, I.R., J.M. Chacama y G.E. Espinosa

1987 El poblamiento prehispánico tardío en el valle de Codpa: una aproximación a la historia regional. Chungara 19:7-61.

Muñoz, I.R, J.M. Chacama y M. Santos

1997 Tambos, Pukaras y Aldeas, evidencias del poblamiento humano prehispánico tardío y de contacto indígena-europeo en el extremo norte de Chile: análisis de los patrones habitacionales y nuevas dataciones radiométricas. Diálogo Andino 16:123-191.

Murra, J.V.

1975El control vertical de un máximo de pisos ecológicos en la economía de las sociedades andinas. En Formaciones Económicas y Políticas del Mundo Andino, editado por J.V. Murra, pp. 59-115. Instituto de Estudios Peruanos, Lima. 1976 Los límites y las limitaciones del "archipiélago vertical”, en los Andes. Anales de la Universidad del Norte 10:141-146.

Nielsen, A.E.

2007 Armas significantes: tramas culturales, guerra y cambio social en el sur andino prehispánico. Boletín del Museo Chileno de Arte Precolombino 12(1):9-41.

Niemeyer, H. y V. Schiappacasse

1981 Aportes al conocimiento del Período Tardío del extremo norte de Chile: análisis del sector Huancarane del valle de Camarones. Chungara 7:3-103.

Niemeyer, H., V. Schiappacasse e I. Solimano

1972-73 Padrones de poblamiento en la quebrada de Camarones. Actas del VI Congreso de Arqueología Chilena, pp. 115-137.

Núñez, L.

1982 Temprana emergencia del sedentarismo en el desierto chileno: Proyecto Caserones. Chungara 9:80-123.

Núñez, P.
1983 Aldeas tarapaqueñas, notas y comentarios. Chungara 10:29-37.

Oakland, A.

1992 Textiles and Ethnicity: Tiwanaku in San Pedro de Atacama, North Chile. Latin American Antiquity 3(4):316-340.

Ponce, $\mathrm{C}$.

1972 Tiwanaku: Espacio, Tiempo y Cultura. Ensayo de Síntesis Arqueológica. Academia de Ciencias de Bolivia, La Paz.

Romero, A.

2005 Organización Social y Economía Política en la Prehistoria Tardía de los Valles de Arica (1.100-1.530). Memoria para optar al Título Profesional de Arqueólogo. Universidad de Chile, Santiago.

Rothhammer, F. y C.M. Santoro

$2001 \mathrm{El}$ desarrollo cultural en el valle de Azapa, extremo norte de Chile y su vinculación con los desplazamientos poblacionales altiplánicos. Latin American Antiquity 12(1):59-66.

Santoro, C.M., J. Hidalgo y A. Osorio

1987 El Estado Inka y los grupos étnicos en el sistema de riego de Socoroma. Chungara 19:71-92.

Santoro, C.M., A. Romero, V.G. Standen y A. Torres

2004 Continuidad y cambio en las comunidades locales, períodos Intermedio Tardío y Tardío, Valles Occidentales del área Centro Sur Andina. Chungara Revista de Antropología Chilena Número Especial, Tomo I, pp. 235-247.

Schiappacasse, V., V. Castro y H. Niemeyer

1989 Los desarrollos regionales en el Norte Grande. En Prehistoria, desde sus Orígenes hasta los Albores de la Conquista, editado por J. Hidalgo, V. Schiappacasse, H. Niemeyer, C. Aldunate e I. Solimano, pp. 181-220. Editorial Andrés Bello, Santiago.

Thompson, L.G., E. Moseley-Thompson, J.F. Bolsan y B.R. Cocí 1985 A 1500-year Record of Tropical Precipitation in Ice Cores from the Quelccaya Ice Cap, Peru. Science 229:971-973.

Torres-Rouff, C. M.A Costa-Junqueira y A. Llagostera 2005 Violence in times of change: the Late Intermediate Period in San Pedro de Atacama. Chungara Revista de Antropología Chilena 37:75-83.

Uribe, $\mathrm{M}$.

2006 Acerca de la complejidad, desigualdad y el Complejo Cultural Pica-Tarapacá en los Andes Centro Sur (1000-1450 DC). Estudios Atacameños 31:91-114.

Uribe, M. y C. Agüero

2001 Alfarería, textiles y la integración del Norte Grande de Chile a Tiwanaku. En Huari y Tiwanaku: Modelos vs. Evidencias. Boletín de Arqueología PUCP 5:397-426.

Uribe, M., L. Sanhueza y F. Bahamondes

2007 La cerámica prehispánica tardía de Tarapacá, sus valles interiores y costa desértica, Norte de Chile (ca. 900-1.450 d.C.): una propuesta tipológica y cronológica. Chungara Revista de Antropología Chilena 39:143-170. 
